\title{
Shifts in euro area Beveridge curves and their determinants
}

\author{
Boele Bonthuis ${ }^{1,2^{*}}$, Valerie Jarvis ${ }^{3 \dagger}$ and Juuso Vanhala ${ }^{4 \dagger}$
}

\author{
*Correspondence: \\ boele.bonthuis@bundesbank.de \\ ${ }^{\dagger}$ Equal contributors \\ 1 Deutsche Bundesbank, \\ Wilhelm-Epstein-Strasse 14, 60431 \\ Frankfurt, Germany \\ ${ }^{2}$ University of Amsterdam, \\ Amsterdam, The Netherlands \\ Full list of author information is \\ available at the end of the article
}

\begin{abstract}
This paper analyses euro area Beveridge curves at the euro area aggregate and country level over the past 25 years. Using an autoregressive distributed lag model, we find a significant outward shift and flattening of the euro area Beveridge curve since the onset of the crisis, but considerable heterogeneity at country level. We test for factors underlying these developments using the local projection method of Jordà (Am Econ Rev 95(1):161-182, 2005). Skill mismatch and high shares of construction workers, as well as high home ownership rates appear strong determinants of the outward shifts in Beveridge curves. Higher female participation rates mitigate these effects.
\end{abstract}

JEL Classification: J62, J63, E24, E32

Keywords: Beveridge curve, Crisis, Unemployment, Labour shortages, Vacancies

\section{Introduction}

Distinguishing between high unemployment rates that are predominantly due to cyclical factors-most notably, a lack of labour demand-or due to wider supply-side factorssuch as a mismatch in the attributes of labour and those required by employers-is vital for effective policy. The Beveridge curve is widely used as a succinct summary of the overall state of the labour market and to distinguish structural shifts from cyclical developments. It traces a (predominantly) negative relationship between unemployment rates and vacancy rates over the course of a business cycle, with low unemployment and high vacancies in expansionary phases and vice versa in contractions.

This paper analyses euro area Beveridge curves over the past 25 years, at both the aggregate euro area level and at country level, focusing in particular on Beveridge curve developments since the onset of the global financial crisis. In the initial stages of the global economic and financial crisis, vacancy rates fell sharply, while unemployment rates rose across almost all euro area economies. Since 2009, vacancy rates have recovered somewhat in many countries, but unemployment rates have remained high or kept rising, suggesting outward shifts in Beveridge curves. Such shifts in the Beveridge curve are of particular interest in times of crisis, since they are suggestive of structural changes in the labour market. Our aim is to identify deviations from the pre-crisis Beveridge curves and to isolate potential preconditions (that tend to make such moves more likely) and salient structural factors influencing these movements.

(c) The Author(s). 2016 Open Access This article is distributed under the terms of the Creative Commons Attribution 4.0 International License (http://creativecommons.org/licenses/by/4.0/), which permits unrestricted use, distribution, and reproduction in any medium, provided you give appropriate credit to the original author(s) and the source, provide a link to the Creative Commons license, and indicate if changes were made. 
Our analysis builds on a number of earlier studies. Borsch-Supan (1991) tests for structural shifts in unemployment as a consequence of recessions in a panel of German federal states from 1963 to 1988. Shift periods are identified by visual inspection of regional Beveridge curves, so as to specify shift dummies, which are then tested for statistical significance. Wall and Zoega (2002) use a similar, though two-stage, approach: firstly, identifying shifts in the Beveridge curve, before trying to explain the shifts by means of institutional variables. Examining Beveridge curves and its shifts for Australia, Groenewold (2003) suggests coefficients of a similar magnitude to Wall and Zoega (2002) and confirms the importance of worker characteristics as a major determinant of increased structural unemployment. Our autoregressive distributed lag (ARDL) specification is a dynamic variation of the basic OLS model originally applied to the USA by Valletta (2005), who estimates a reduced form equation using a similar method to Borsch-Supan (1991). Valletta (2005) does not fully isolate the structural shifts in Beveridge curve movements, since Beveridge curves are able to move back and forth from year to year, because of the use of yearly dummies. Our method restricts the movements to specific-and rather more protracted-periods. ${ }^{1}$ To reproduce the dynamics of the Beveridge curve accurately, we augment these models into an autoregressive distributed lag model. In the second step of our analysis, we investigate what has driven the shifts of the euro area Beveridge curves. In particular, we study the pre-crisis cross-country differences of potential drivers, or preconditions, of these shifts using the local projections method of Jordà (2005) where we apply specifications developed in Teulings and Zubanov (2014).

Our econometric analysis uses an ARDL model to test for the statistical significance of observed shifts and changes in the slope of the Beveridge curve since the onset of the global financial and economic crisis for both the euro area aggregate and the individual countries. We find a significant shift and change in the slope of the euro area Beveridge curve since the onset of the crisis, but considerable heterogeneity at country level. We extend our analysis to examine the likely preconditions underlying the observed developments, evaluating a range of country-specific factors-including labour force characteristics, sectoral employment composition and financial conditions-using the local projection method of Jordà (2005). We find evidence for skill mismatch, geographical mismatch and sectoral mismatch. However, only the latter seems to have a more permanent effect on the position of the Beveridge curve. A high share of low-skilled workers, a high home ownership rate and a high share of workers (previously) employed in the construction sector tend to shift the Beveridge curve outward in case of a negative shock. A high pre-crisis share of female workers in the labour force on the other hand tends to mitigate these effects.

The Beveridge curve has raised a lot of interest in the literature lately, but with some exceptions (e.g. Bouvet (2012), ECB (2002), European Commission (2011b) and Hobijn and Sahin (2013)), most studies are country specific, in part due to the lack of long and comparable cross-country vacancy series. ${ }^{2}$ Our reliance on the European Commission's survey of employers' perceptions of labour shortages in manufacturing permits a disaggregated cross-country approach incorporating all euro area economies.

The paper proceeds as follows. Section 2 briefly describes the data and presents a graphical depiction of developments of the euro area Beveridge curve over the past two decades. Section 3 examines the statistical significance of observed shifts using an ARDL model. 
Section 4 extends the analysis to examine factors underlying the observed shifts. Section 5 concludes.

\section{Overview of Beveridge curve developments}

\subsection{The data}

The basis for our analysis is quarterly data on unemployment and vacancy developments. To ensure cross-country comparability, throughout this paper, we use Eurostat's harmonised unemployment rate for the euro area countries and the aggregate. Since official data on job vacancy developments are still somewhat embryonic, two vacancy series are considered: firstly, Eurostat's job vacancy rates for the euro area as a whole; ${ }^{3}$ secondly, the longer-running European Commission series of employers' perceptions of labour shortages in manufacturing. These data are taken from the European Commission's regular Surveys of Business Confidence-specifically the aggregated responses from the question relating to employers' perceptions of labour shortages as limits to business. ${ }^{4}$ Advantages of these data over Eurostat's job vacancy rates stem from the longer availability of the series (for most countries, from at least 1990) and their seasonally adjusted form. These data have a very similar cyclical pattern as Eurostat's job vacancy rates, correlating well with vacancy movements in the Eurostat series, therefore offering a reasonable approximation of real time labour demand developments (see Additional file 1: Table S1 for a correlation matrix).

In our analysis of the drivers of the Beveridge curve shifts, we use data on sectoral, skill and gender (un-)employment figures. In an attempt to isolate the impact of financial factors on labour market outcomes, we assess also the impact of home ownership rates and the inverted financial shortage index of the European Commission series of employers' perceptions of financial shortages in manufacturing (European Commissions' Surveys of Business Confidence) as a limit to business as a measure of financial slack.

\subsection{Beveridge curve developments in the euro area}

Figure 1a shows developments in the aggregate euro area Beveridge curve since 2006Q1 on the basis of Eurostat job vacancy data. The counterclockwise movements of the precrisis observations trace the typical business cycle pattern of falling unemployment as

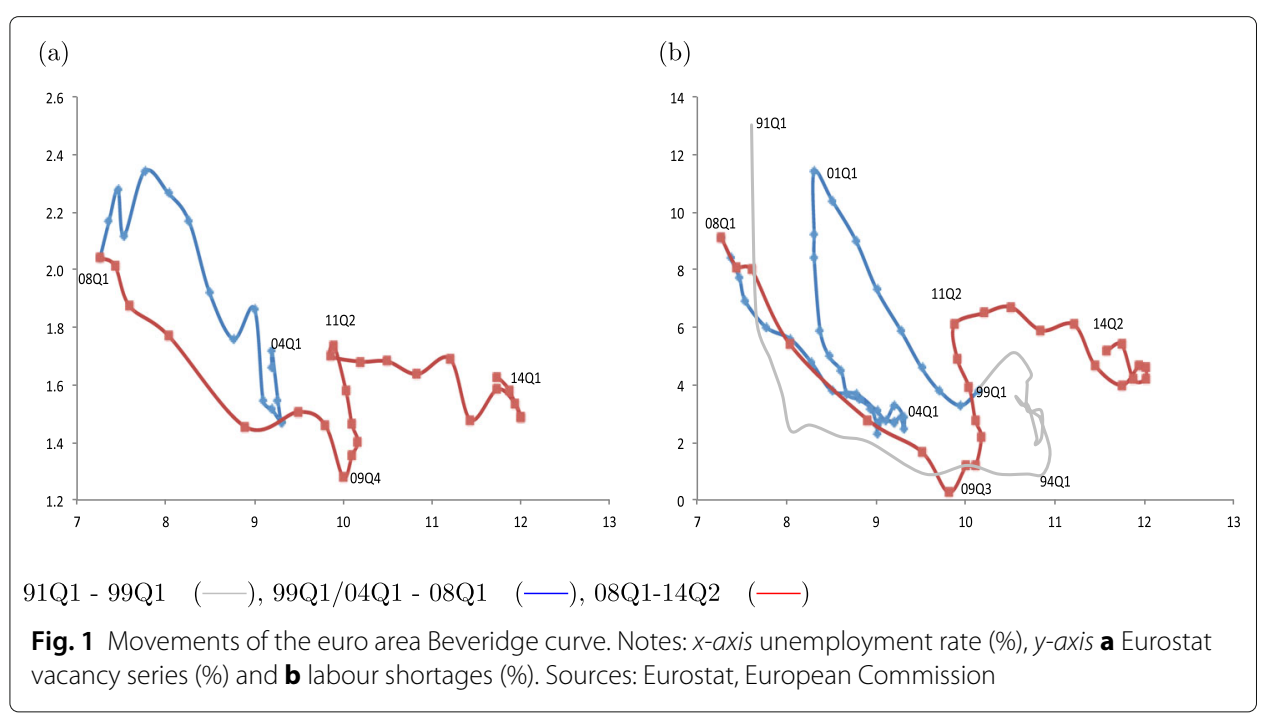


vacancies increased, thus tightening the labour market. As the recession took hold, the vacancy rate fell sharply and unemployment increased strongly, represented by a southeasterly movement in the Beveridge coordinates. This pattern continued even after the resumption of economic growth (from 2009Q3). However, following the partial recovery in the aggregate euro area vacancy rate, the unemployment rate has not declined.

Figure $1 \mathrm{~b}$ makes use of the time series on labour shortages to trace the euro area Beveridge curve since 1990. This suggests that, following an outward shift in the Beveridge curve in the late 1990s, over the course of much of the first decade of economic and monetary union (EMU), euro area unemployment appears to have become considerably more responsive to vacancy developments, resulting in an inward shift in the euro area Beveridge curve during the middle years of the 2000s (blue lines in Fig. 1b). This longer series reveals a clear deviation from the previous unemployment-vacancy relationship since the onset of the crisis (2008Q1), suggestive of the emergence of structural problems in some euro area labour markets-albeit masking considerable, well-documented cross-country heterogeneity. ${ }^{5}$

Figure 2 computes the average degree of Beveridge-style unemployment "elasticities"i.e. the estimated proportional reactions from dividing changes in the unemployment rate by changes in labour shortages - for all euro area countries for the pre-crisis period and since the onset of the financial crisis. ${ }^{6}$ It shows that the reaction of unemployment to changing labour shortages during the crisis was typically much larger than during the pre-crisis period. Moreover, Fig. 2 illustrates clearly the strong degree of cross-country heterogeneity in unemployment responses to subdued labour demand following the 2008 recession, with disproportionately large "elasticities" estimated for Spain, Greece, Italy, Portugal and France in stark contrast to the markedly lower elasticities of Malta, Belgium, Slovenia, Finland and Austria.

\section{Econometric analysis of euro area Beveridge curve movements}

To test for statistical significance of suggested changes the models of the unemploymentvacancy relationship across the euro area, we apply an autoregressive distributed lag

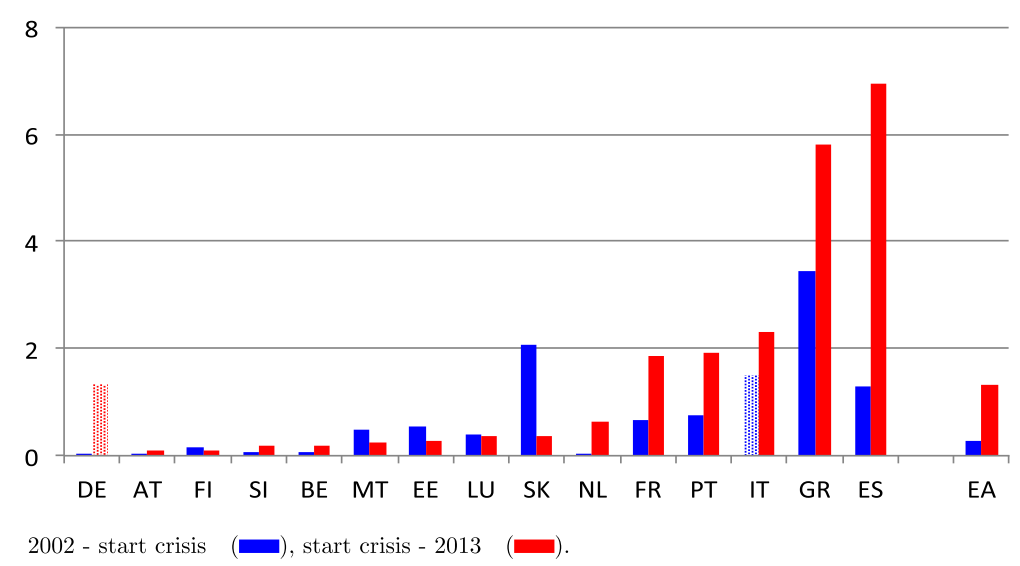

Fig. 2 Summary of Beveridge curve developments. Notes: Elasticity (y-axis) defined as the total change in unemployment divided by the total change in labour shortages: $|\Delta U / \Delta L S|$. Both in percentage points. Germany (crisis-13) and Italy (02-crisis) have both declining labour shortages and declining unemployment. Sources: Eurostat, European Commission, own calculations 
(ARDL) model to a basic Beveridge curve specification, estimated both at aggregate and at country level: ${ }^{7}$

$$
\begin{aligned}
U_{t}= & \beta_{0}+\sum_{i=1}^{p} \beta_{i, 1} U_{t-i}+\sum_{j=0}^{q} \beta_{j, 2} L S_{t-j}+\sum_{j=0}^{q} \beta_{j, 3} L S_{t-j} D_{t-j}^{\mathrm{cri}}+ \\
& \beta_{4} D_{t}^{\mathrm{cri}}+\beta_{5} D_{t}^{\mathrm{emu}}+\beta_{6} D_{t}^{\mathrm{rec}}+\epsilon_{t}
\end{aligned}
$$

where $U_{t}$ is the official Eurostat harmonised unemployment rate and $L S_{t}$ is the labour shortage variable serving as proxy for vacancy developments. ${ }^{8}$ To test the impact of the crisis on euro area Beveridge curves, we incorporate a dummy variable, $D^{\text {cri }}$, taking a value of one from the first of at least two consecutive quarters of negative quarter-onquarter GDP growth after 2007 to the end of the series, so as to identify the period from the start of the crisis until the end of the sample, whilst allowing all crisis periods to be country specific. We also interact the crisis dummy with labour shortages $\left(L S * D^{\text {cri }}\right)$ to identify changes in the slope of the Beveridge curve. To identify possible shifts in the Beveridge curve over the course of monetary union, a dummy variable, $D^{\mathrm{emu}}$ (taking a value of 1 at each country's entry into EMU to the end of the sample), is used. In our model, we thus effectively allow for three different Beveridge curve positions: a 1990s "baseline," the EMU period and the crisis period. Finally, since elevated unemployment can simply be due to an economy being in a recession, we include $D^{\text {rec }}$ which takes a value of one from the first of at least two consecutive quarters of negative quarter-on-quarter GDP growth. This way we can distinguish between high unemployment due to cyclical factors $\left(D^{\text {rec }}\right)$ and an outward shift of the Beveridge curve due to more structural factors $\left(D^{\mathrm{cri}}\right)$.

The model is estimated on quarterly data covering the period 1990Q1 to $2015 \mathrm{Q} 4 .^{9}$ So as to improve the comparability of the Beveridge curve parameter estimates across countries (by taking specific account of idiosyncratic cross-country variability in reported labour demand conditions, unrelated to business cycle developments), each country's labour shortage data were mean-adjusted. Moreover, country-specific differences in lag structure of unemployment adjustment were taken into account (by allowing $p$ and $q$ to differ across countries, according to country-specific values suggested by AIC and BIC). This specification produces stationary results, with broadly stable $\left(\sum_{i} \beta_{i, 1}<1\right)$ and downward-sloping $\left(\sum_{j} \beta_{j, 2}<0\right)$ Beveridge curves for most countries. ${ }^{10}$

Table 1 summarises the main results for the four biggest euro area economies, as well as for a specification based on aggregate euro area data. Beginning with the aggregate results (column 1), the sum of coefficients on the lagged unemployment rate is large and highly significant, as anticipated, consistent with the considerable persistence in typically observed in euro area unemployment dynamics. As expected, the labour shortage variable, $L S_{t}$, displays the necessary negative coefficient, confirming a well-behaved inverse relationship between unemployment and vacancies which underlies the Beveridge curve.

Turning to the dummy variables, EMU looks to have had a significant and favourable impact on euro area labour markets, coinciding with an inward shift in the euro area Beveridge curve. To some extent, this inward shift could be a result of structural labour market reforms which accompanied EMU membership in several euro area countries. As regards the impact of the crisis, $D^{\text {cri }}$ is both positive and highly significant, suggestive of a strong outward shift in the euro area Beveridge curve since the onset of the recession and 
Table 1 Beveridge curve estimation

\begin{tabular}{|c|c|c|c|c|c|}
\hline Dependent & (1) & (2) & (3) & (4) & (5) \\
\hline var.: $U_{t}$ & EA & $\mathrm{DE}$ & ES & $F R$ & $\mathrm{IT}$ \\
\hline \multirow[t]{2}{*}{$U_{t-1}$} & $1.53^{* * *}$ & $1.99 * * *$ & $1.57^{* * *}$ & $1.25^{* * *}$ & $1.03^{* * *}$ \\
\hline & $(0.11)$ & $(0.10)$ & $(0.07)$ & $(0.10)$ & $(0.10)$ \\
\hline \multirow[t]{2}{*}{$U_{t-2}$} & $-0.57^{* * *}$ & $-1.38^{* * *}$ & $-0.63^{* * *}$ & $-0.36^{* * *}$ & -0.06 \\
\hline & $(0.20)$ & $(0.18)$ & $(0.07)$ & $(0.09)$ & $(0.10)$ \\
\hline \multirow[t]{2}{*}{$U_{t-3}$} & 0.20 & $0.36^{* * *}$ & & & \\
\hline & $(0.20)$ & $(0.09)$ & & & \\
\hline \multirow[t]{2}{*}{$U_{t-4}$} & $-0.42^{* *}$ & & & & \\
\hline & $(0.19)$ & & & & \\
\hline \multirow[t]{2}{*}{$U_{t-5}$} & $0.20^{* *}$ & & & & \\
\hline & $(0.09)$ & & & & \\
\hline \multirow[t]{2}{*}{$L S_{t}$} & $-0.02^{* * *}$ & $-0.03^{*}$ & -0.05 & $-0.02^{* * *}$ & $-0.02^{*}$ \\
\hline & $(0.01)$ & $(0.01)$ & $(0.05)$ & $(0.01)$ & $(0.01)$ \\
\hline \multirow[t]{2}{*}{$L S_{t-1}$} & & -0.01 & -0.07 & & \\
\hline & & $(0.02)$ & $(0.05)$ & & \\
\hline \multirow[t]{2}{*}{$L S_{t-2}$} & & 0.02 & -0.00 & & \\
\hline & & $(0.02)$ & $(0.05)$ & & \\
\hline \multirow[t]{2}{*}{$L S_{t-3}$} & & -0.00 & -0.03 & & \\
\hline & & $(0.01)$ & $(0.05)$ & & \\
\hline \multirow[t]{2}{*}{$D_{t}^{c r i} L S_{t}$} & $0.02^{*}$ & 0.02 & 0.06 & 0.02 & -0.07 \\
\hline & $(0.01)$ & $(0.01)$ & $(0.07)$ & $(0.02)$ & $(0.08)$ \\
\hline \multirow[t]{2}{*}{$D_{t-1}^{c r i} L S_{t-1}$} & & -0.03 & 0.11 & & \\
\hline & & $(0.02)$ & $(0.08)$ & & \\
\hline \multirow[t]{2}{*}{$D_{t-2}^{c r i} L S_{t-2}$} & & $0.05^{* * *}$ & 0.10 & & \\
\hline & & $(0.02)$ & $(0.08)$ & & \\
\hline \multirow[t]{2}{*}{$D_{t-3}^{c r i} L S_{t-3}$} & & $-0.03^{* *}$ & $-0.13^{*}$ & & \\
\hline & & $(0.01)$ & $(0.07)$ & & \\
\hline \multirow[t]{2}{*}{$D_{t}^{\mathrm{emu}}$} & $-0.07^{* * *}$ & 0.02 & $-0.28^{* * *}$ & $-0.15^{* *}$ & $-0.19^{* * *}$ \\
\hline & $(0.03)$ & $(0.03)$ & $(0.10)$ & $(0.07)$ & $(0.07)$ \\
\hline \multirow[t]{2}{*}{$D_{t}^{c r i}$} & $0.09^{* *}$ & $-0.10^{* *}$ & $0.53^{* * *}$ & $0.14^{* *}$ & -0.02 \\
\hline & $(0.04)$ & $(0.04)$ & $(0.16)$ & $(0.05)$ & $(0.21)$ \\
\hline \multirow[t]{2}{*}{$D_{t}^{\mathrm{rec}}$} & $0.12^{* *}$ & 0.04 & $0.33^{* * *}$ & 0.10 & $0.18^{* * *}$ \\
\hline & $(0.05)$ & $(0.03)$ & $(0.12)$ & $(0.07)$ & $(0.06)$ \\
\hline \multirow[t]{2}{*}{ Cons. } & $0.51^{* * *}$ & $0.22^{* *}$ & $1.05^{* * *}$ & $1.09^{* * *}$ & $0.32^{*}$ \\
\hline & $(0.10)$ & $(0.09)$ & $(0.25)$ & $(0.30)$ & $(0.17)$ \\
\hline Obs. & 104 & 97 & 104 & 96 & 104 \\
\hline $\operatorname{Adj}-R^{2}$ & 0.99 & 1.00 & 1.00 & 0.97 & 0.98 \\
\hline RMSE & 0.10 & 0.10 & 0.27 & 0.17 & 0.25 \\
\hline
\end{tabular}

Standard errors in parentheses. Sample period: 1990Q1-2014Q1

${ }^{* * *} p<0.01,{ }^{* *} p<0.05,{ }^{*} p<0.1$

the interaction term $\left(L S * D^{\text {cri }}\right)$ is both positive and significant reflecting an overall decline in the responsiveness of unemployment to vacancy developments. Finally, the positive and significant coefficient on $D^{\text {rec }}$ suggests that unemployment in a recession is in general elevated, deviating slightly from the typical Beveridge curve. However, this effect is temporary and is absent in normal times.

Turning to the results of the four largest euro area countries, the model performs well for Germany, Spain and France. The coefficient on the crisis dummy for Germany is 
strongly significant but negative, suggestive of an inward shift of the German Beveridge curve since the crisis. This is likely to reflect, in part, lagged returns following the implementation of the earlier Hartz labour market reforms, undertaken from the mid-2000s in Germany, as well as widespread reliance on short-time working schemes (Kurzarbeit) and flexible use of working time accounts over the crisis, which help provide both firms with internal adjustment mechanisms with which to adjust labour input, rather than the need to adjust headcount.

For France and Spain, meanwhile, the model suggests strong and significant outward shifts in the Beveridge curve. Results for Spain, in particular, show a marked shift in the underlying unemployment-vacancy relationship since the onset of the crisis, as evidenced by the significant positively signed shift dummy, $D^{\text {cri }}$. While all parameters are estimated with the correct signs for Italy, the model does not perform well-not least, as the system might be explosive, with almost a unit root on the lagged dependent variables. Results for the smaller euro economies were typically less clear-cut, particularly in the light of robustness testing (undertaken for all economies modelled) ${ }^{11}$; nevertheless, results of a slope change were also suggested for Belgium (less responsive) and Portugal (more responsive) in addition to the strong and robust results already detailed for the euro area, France and Spain.

\section{What drives shifts in euro area Beveridge curves?}

For policy purposes, it is not sufficient to know whether shifts in the Beveridge curves are evident, but rather to understand what is driving those shifts. In this section, we investigate the role of labour force characteristics, sectoral composition as well as financial factors in driving outward shifts in euro area Beveridge curve(s) using the local projection method of Jordà (2005) augmented with specifications developed in Teulings and Zubanov (2014). ${ }^{12}$

The idea behind the local projections is to compute impulse responses without estimating an underlying multivariate dynamic system. The impulse response functions are estimated directly from the data by regressing future values of unemployment on precrisis unemployment and vacancies. This method essentially estimates how unemployment developed given pre-crisis Beveridge curve data and therefore gives an indication of deviations of unemployment from the pre-crisis Beveridge curve. The advantage of this method over for instance a fully fledged VAR model is that it is robust to misspecifications. Additionally, it allows for a more flexible specification which we will explore in the second part of this section when we investigate the drivers behind the Beveridge curve shift.

Compared to the previous section, using impulse response functions allows the Beveridge curve automatically to move back to its original position. Whether the Beveridge curve has shifted out permanently can simply be assessed by looking whether the impulse response function moves back to 0 (or at least becomes insignificant).

We start with a Beveridge curve specification similar to the previous section using the local projections method proposed by (Jordà 2005):

$$
U_{c, t+k}=\beta_{c, 0}^{\prime}+\sum_{i=1}^{p} \beta_{i k, 1}^{\prime} U_{c, t-i}+\sum_{j=0}^{k+q} \beta_{j k, 2}^{\prime} L S_{c, t+k-j}+\sum_{l=0}^{k+r} \beta_{l k, 3}^{\prime} D_{c, t+k-l}+\epsilon_{c, t}
$$


in which $D_{c, t}$ takes the value of 1 at the time of a shock but is 0 otherwise. Shocks are defined as the start of at least two consecutive quarters of negative quarter-on-quarter GDP. $\beta_{c, 0}$ is the country fixed effects (we ignore the EMU dummy for the moment). For each period $k$ following the start of the financial crisis, we can estimate this equation forward, obtaining the impulse response function described by the parameter $\beta_{0 k, 3}$. We follow Teulings and Zubanov (2014) by retaining all manifestations of the crisis variable up to period $k$. This way, we allow later shocks (such as the sovereign debt crisis) to influence the position of the Beveridge curve while picking up only the effect of the financial crisis in our estimation of the crisis dummy and not and subsequent shocks. Similarly, we include labour shortages up to period $k \cdot{ }^{13}$

In this setup, we can unfortunately not test directly for a change of the slope of the Beveridge curve. However, we can give an indication of the deviation of labour shortages from the pre-crisis Beveridge curve. In addition to the above specification, we will estimate a similar conditional impulse response function for labour shortages, reversing Eq. 2 and taking $L S_{t+k}$ to the left-hand side.

This way we can test whether labour shortages deviate significantly from the pre-crisis Beveridge curve giving an indication of the possibility of a slope change.

To determine which sample of countries and time period to use in our panel, we test for a common slope across groups of countries and for different sample lengths (see results in Additional file 1: Table S7). We find that restricting the sample to the EMU period and including only "original" euro area countries (i.e. countries that joined the euro before 2002) with a well-specified Beveridge curve returns the best results for the poolability test. Several of these countries-Greece, Ireland, Portugal and Spain-were subsequently subject to intense financial stress, resulting in eventual reliance on international aid programmes, and are henceforth referred to collectively as the "stressed" economies. ${ }^{14}$

Figure 3a shows the results of the local projection method for the baseline crisis dummy with a $95 \%$ confidence interval using Eq. 2. We observe a persistent and significant rise in the unemployment rate-corrected for the vacancy rate-which is consistent with the
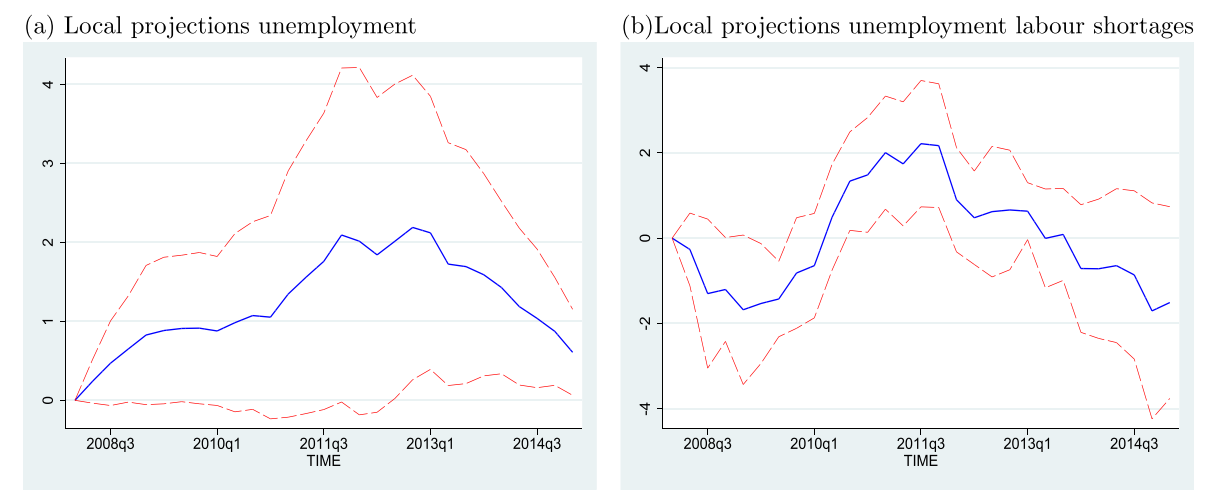

Local projection $(-), 95 \%$ confidence interval (-- )

Fig. 3 Baseline results. Notes: Local projection of the crisis dummy for both unemployment and labour shortages 
(permanent) shift of the euro area aggregate Beveridge curve in the previous section. The fact that the impulse response function stays significantly positive can be interpreted as tentative evidence of a considerable long-run effect of the crisis on unemployment (i.e. permanent outward shift of the Beveridge curve). However, the trend does seem to be reverting to 0 at the end of our sample, and an extension of our sample may well prove that the effect is not permanent. Labour shortages do not seem to deviate significantly from the pre-crisis Beveridge curve in the long run (see Fig. 3b). In the short run, labour shortages seem to drop faster than unemployment rises but they also recover faster, confirming the typical counterclockwise movement of the Beveridge curve.

Splitting the countries between two distinct groups of stressed economies (containing Spain, Portugal and Greece) and the rest (Austria, Belgium, Germany, Finland, France and the Netherlands) suggests a strong dichotomy. While the whole sample does not seem to shift outward, the stressed countries exhibit a (permanent) large and significant outward shift (see Fig. 4). Again, the impulse response function is significantly different from 0 at the end of the sample, which is an indication of an outward shift, but the trend is reverting to 0 .

Turning to the drivers behind the Beveridge curve shifts, we follow for a large part Bernal-Verdugo et al. (2013). Rewriting Eq. 2 as

$$
\begin{aligned}
U_{c, t+k} & =\beta_{c, 0}^{\prime \prime}+\sum_{i=1}^{p} \beta_{i k, 1}^{\prime \prime} U_{c, t-i}+\sum_{j=0}^{k+q} \beta_{j k, 2}^{\prime \prime} L S_{c, t+k-j} \\
& +\sum_{l=0}^{k+r} \beta_{l k, 3}^{\prime \prime} D_{c, t+k-l}+\sum_{l=0}^{k+r} \beta_{l k, 4}^{\prime \prime} D_{c, t} N_{c, t}+\epsilon_{c, t+k}
\end{aligned}
$$

in which $N_{c, t}$ is a matrix with variables influencing the position of the Beveridge curve. ${ }^{15}$ To test for the effect of these variables during the crisis, we interact them with the crisis dummy. ${ }^{16}$ This way, we can compare the impact of the crisis (reflected in the simple crisis dummy) on the position of the Beverige curve with features most likely to act as preconditions for a Beveridge curve shift (reflected in the interaction term). Since the interaction term deviates from zero only at crisis impact, we can exclude the possibility of reverse
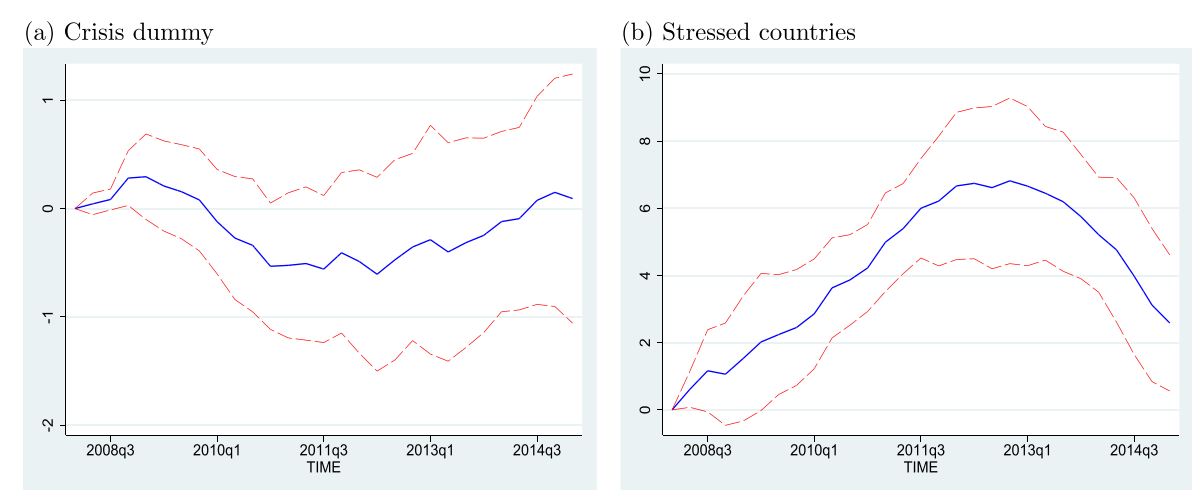

Local projection $(-), 95 \%$ confidence interval (-- )

Fig. 4 Stressed vs. non-stressed countries. Notes: Stressed countries are Spain, Portugal and Greece 
causality; only the pre-crisis values of our drivers influence the position of the Beveridge curve.

\subsection{Labour force characteristics}

Strong increases in unemployment have been heavily concentrated among the low-skilled (and young) people in many euro area countries. In Fig. 5, we plot the projections for the baseline crisis dummy and the share of low-skilled workers. ${ }^{17}$ The results in Fig. 5 confirm that labour force composition had significant impact on the outward shift of a country's Beveridge curve over the crisis period.

Higher pre-crisis proportions of low-skilled in the labour force-defined as the number of low skilled (employed and unemployed) divided by the total labour force-seem to be an important precondition for a persistent outward shift of a country's Beveridge curve. ${ }^{18}$ One possible explanation is that sectors with a large amount of low-skilled workers were especially hard hit during the crisis (for instance construction and to a lesser extent manufacturing). Restructuring of these sectors and difficulties in reallocating labour to other sectors can lead to permanent losses in employment. However, it should be noted that the impulse response function moves into insignificant territory at the end of our sample, indicating that the share of low-skilled workers is unlikely to be the driver behind a permanent shift of the Beveridge curve.

High shares of women participating in the labour force on the other hand seem to shift the Beveridge curve inward (see the Appendix). ${ }^{19}$ One potential explanation is that the crisis has mainly hit male dominated sectors, whereas public sector employment-where women are typically more strongly represented-has suffered smaller losses. Furthermore, economies with higher female participation are more likely to keep a shock to consumption to a minimum. For households in which income is mainly provided by one of the members of the household, a spell of unemployment is likely to significantly reduce consumption, whereas in a dual-earner household, the effects will be dampened.

However, including these labour force composition indicators does not render the long-term effect of the crisis dummy insignificant. The "unexplained" part of the rise in unemployment is still present. ${ }^{20}$

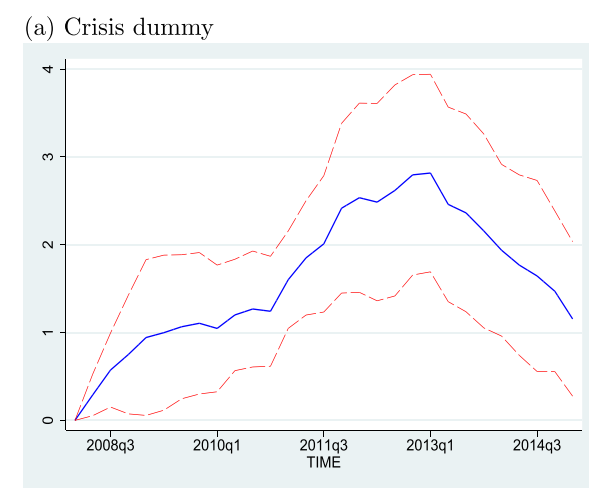

(b) Low skilled

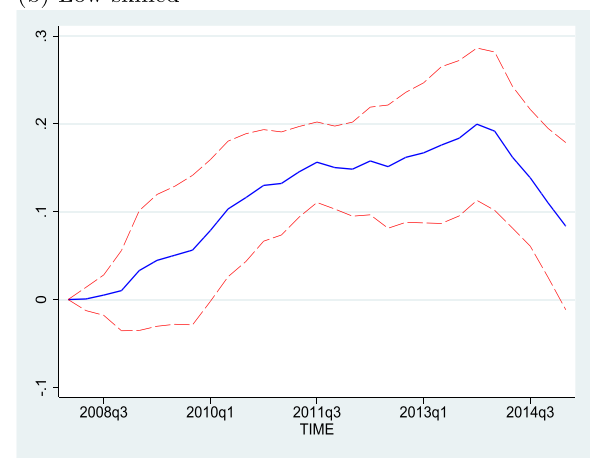

Local projection $(-), 95 \%$ confidence interval (-- )

Fig. 5 Labour force characteristics. Notes: Low skilled: share of the labour force with less than upper secondary education 


\subsection{Sectoral mismatch}

To shed light on the extent to which sectoral developments were a key driver of the observed outward shifts (whereby displaced workers from one sector were not able to reallocate to employment in alternative sectors), we extend our analysis using shares of employment by sector. ${ }^{21}$ Using the NACE2 sectoral breakdown, we include the share of employment in the construction sector as precondition for an potential outward shift in the Beveridge curve. ${ }^{22}$

The construction sector stands out as an important precondition for an outward Beveridge curve shift (see Fig. 6). Heavy job losses in the construction sector have been a common feature of many euro area labour markets since the start of the crisis. Across the euro area as a whole, construction employment declined by roughly $7 \%$ year-onyear-over twice the rate of contraction as in the economy as a whole-at the depths of the crisis; in some countries, losses were higher still (for instance in Spain where construction constituted almost $14 \%$ of employment in the pre-crisis period). Moreover, employment contractions have tended to be rather longer-lived in construction-as job losses began rather earlier than in other sectors and, in some countries have been particularly persistent, resulting in construction employment levels well below their pre-crisis peaks in several euro area economies. Part of the downsizing observed is likely to be permanent, reflecting some correction to previously over-expanded construction sectors in some euro area economies. Displaced construction workers are unlikely to be readily absorbed into other activities with ease. This, coupled with the generally lowskill nature of construction work, is clear prerequisite for the long lasting significantly positive outward shift of the Beveridge curve. As the figure clearly shows, the effect is still present at the end of the sample even though the trend seems to be reverting somewhat.

As with the labour force characteristics, including sectoral composition indicators does not render the long-term effect of the crisis dummy insignificant.

\subsection{Financial conditions}

In an attempt to assess the impact of financial variables on labour market outcomes, finally, we regress observed Beveridge curve developments on rates of home ownership

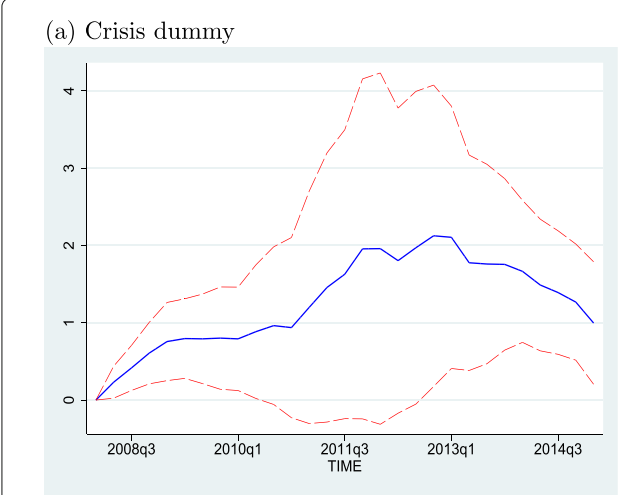

(b) Construction

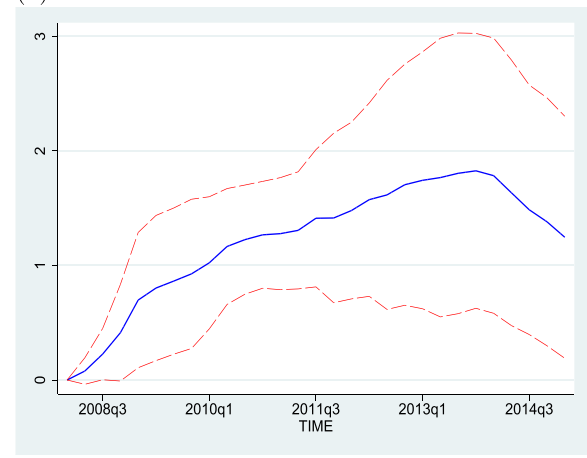

Local projection $(-), 95 \%$ confidence interval (-- $)$

Fig. 6 Sectors. Notes: Construction sector: employment in sector F as share of total employment. NACE2 classification 
and other financial variables as a first attempt to isolate the impact of the credit crunch itself on labour market outcomes.

Figure 7 shows that a high pre-crisis rate of home ownership appears to have a significant and positive effect on the position of the Beveridge curve. One explanation-in common to the findings of several US studies-is that, following a sharp revaluation of asset prices (including domestic real estate) following the credit crunch and the bursting of construction bubbles in several euro area economies, homeowners in negative equity (or those whose homes were subsequently revalued to market rates lower than they had paid ) were left unable (or unwilling) to move to a less severely hit areas. ${ }^{23}$ However, it should be noted that the impulse response function appears to move back into insignificant territory at the end of the sample, meaning that, while the effects are long-lasting, home ownership is unlikely to be a precondition for a permanent shift in the Beveridge curve.

To attempt to evaluate the effect of pre-crisis financial conditions, we also used the European Commission series of employers' perceptions of financial shortages in manufacturing (European Commissions' Surveys of Business Confidence (European Commission (2011a)) as a limit to business, inverted so as to provide an approximate metric of the ease with which credit can be procured (or alternatively, of financial slack). The results were not found to be significant. ${ }^{24}$

As with the previous two tests, including financial conditions in the local projection method does not fully explain the long-term increase in unemployment. The unexplained effect of the crisis dummy is significant throughout our estimated period.

\section{Conclusions}

The labour market consequences of the recent crisis have been heterogeneous across countries and sectors in the euro area. Overall, there are risks that the rise in euro area unemployment over the crisis may become persistent both at the aggregate euro area level and for some of the member economies. Whether the high unemployment rates are due to cyclical factors and a lack of labour demand, or to structural factors such as labour market mismatches, has important policy implications. In this paper, we find evidence for the latter.
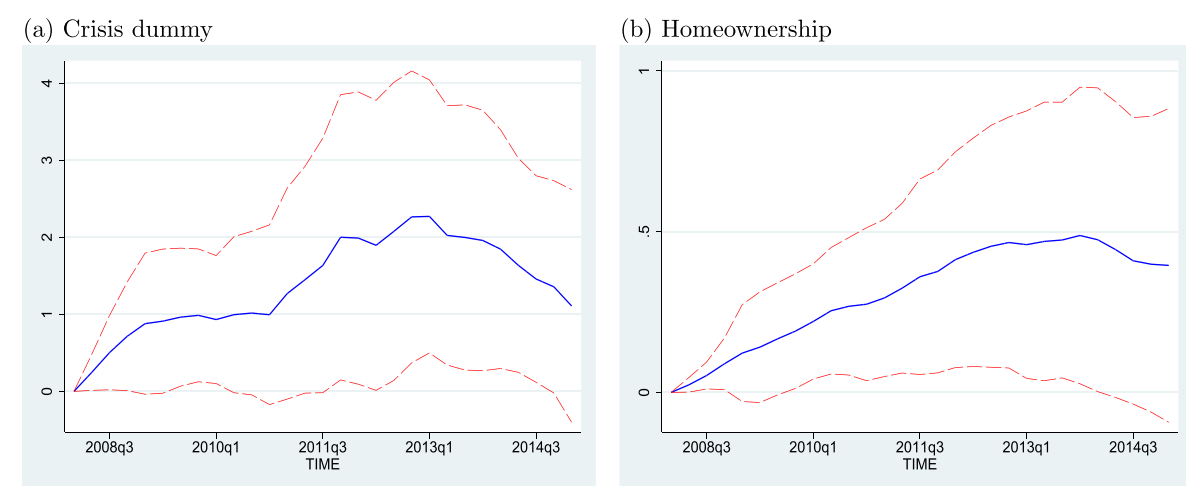

Local projection (- $), 95 \%$ confidence interval (-- )

Fig. 7 Financial conditions. Notes: Home ownership: ownership rate as per cent of the population 
We find a significant shift in the aggregate euro area Beveridge curve since the onset of the crisis, suggestive of a marked increase in labour market mismatch over the subsequent period. At country level, however, there is considerable heterogeneity.

The results from a local projection analysis, designed to isolate the salient structural features influencing Beveridge curve movements, suggest that labour force characteristics-in particular, smaller proportions of lower-skilled workers and a higher proportions of women in the total labour force-significantly decrease the probability of an outward shift. Sectoral factors-particularly, the heavy employment losses in the construction sector-are important determinants of observed Beveridge curve shifts with long-lasting effects. At a more structural level, this paper finds high incidences of home ownership rates also increase the likelihood of outward shifts in Beveridge curves following the onset of a negative shock.

\section{Endnotes}

${ }^{1}$ As a robustness check, we replace our shift dummy with yearly dummies to allow Beveridge curves to move back.

${ }^{2}$ There are an increasing number of recent studies that estimate matching functions and Beveridge curves for the USA, including Barnichon et al. (2012), Barnichon and Figura (2011), Daly et al. (2011 ), Daly et al. (2012), Elsby et al. (2010) and Şahin et al. (2014).

${ }^{3}$ Although job vacancy data are available from Eurostat since 2006Q1, these data are not fully harmonised across countries (e.g. cross-country sectoral and coverage differences).

${ }^{4}$ See European Commission (2011a). Three labour shortages series are available, covering manufacturing, construction and services. We use labour shortages for manufacturing, since this (a) is the longest of the series and (b) has been used extensively in the literature (see, for instance, ECB (2002), European Commission (2011b)). Composite indexes of manufacturing, services and construction labour shortages render largely similar results.

${ }^{5}$ See, for example, ECB (2012) and ECB (2015). Figure 8 in the Appendix shows developments for the four largest euro area economies since 1999. For more on countryspecific Beveridge curve developments over the course of the crisis, see the earlier version of this paper (Bonthuis et al. (2015)).

${ }^{6}$ Additional file 1: Figure S1 shows Beveridge curve profiles for the individual euro area countries

${ }^{7}$ The simplest specification used here follows the spirit of earlier studies by BorschSupan (1991), Wall and Zoega (2002), Groenewold (2003), Valletta (2005) and, more recently, the European Commission (2011b).

${ }^{8}$ For an analysis of the use of vacancy data instead of labour shortages, see Bonthuis et al.(2013).

${ }^{9}$ Data for France and Finland from 1992, for Malta from 2004 and for Slovakia from 2000. The labour shortage series for Ireland stops in 2008. Earlier observations appear exceptionally volatile and outside the range of all subsequent observations in these series.

${ }^{10}$ Only for Malta, a Beveridge curve with stationary standard errors cannot be found; additionally, its Beveridge curve is not downward sloping. Ireland, Italy, Luxembourg and 
Slovakia have stability issues since the sum of the lagged-dependent variables is not significantly different from unity. For Cyprus, Ireland, Malta, Luxembourg and Slovakia, it is not immediately clear that the Beveridge curve is downward sloping.

${ }^{11}$ For individual country results, see Additional file 1: Table S2. Robustness checks included alternative functional forms, testing for asymmetries over (country-specific) recessions and, in response to the suggestions of an anonymous referee, allowing the Beveridge Curve "free movement" in unemployment-vacancy space-econometrically, by replacing our crisis dummy with less restrictive year dummies (similar to Valletta (2005)), beginning in 2008 (see Additional file 1: Table S5). Robustness tests confirm clear evidence of outward shifts in the Beveridge curves of the euro area and Spain. For France, the picture is less clear, with considerable year-to-year jumps in the position of the French Beveridge curve (to the extent that no shift cannot be excluded). Nevertheless, using a specification with year dummies results in marked changes also in the slope coefficient, suggestive of an alternative means of deviating from the pre-crisis Beveridge curve. For Greece, adding yearly dummies resulted in a Beveridge curve that is not well behaved.

${ }^{12}$ Institutional variables were tested in our analysis, but robust results were not found. Often, institutional variables do not work well in econometric analyses-due, in large part, to data limitations, such as short and infrequent series; the inherent need for heavy synthesis of complex cross-country indicators in very different institutional settings; lack of cross-country variation and lack of temporal variation. Given these and associated problems, it was difficult to include institutional features directly in our econometric analysis. For an extended discussion of institutional variables in a Beveridge curve analysis, see Bonthuis et al. (2013).

${ }^{13}$ As Teulings and Zubanov (2014) note, the forecast $k$ periods ahead will not only be influenced by crises that occurred before or at period $t$ but also by any crisis occurring between $t$ and the forecast horizon $k$. A similar argument applies to the labour shortage variable. This is of particular importance in our analysis since rising unemployment as such does not necessarily constitute an outward shift of the Beveridge curve: if vacancies drop as well, this represents simply a movement along a given Beveridge curve towards the extremes.

${ }^{14}$ As another robustness check, we use the local projection method of Jordà (2005) directly, excluding contemporaneous observations of the crisis and labour shortages from the projections.

${ }^{15}$ Expressed as deviation from the euro area aggregate at the start of the crisis of which we take the pre-crisis four quarter average. This means for factor $n$, we take $\left(\sum_{i=0}^{3} n_{c, t-i}-\sum_{i=0}^{3} n_{e a, t-i}\right) / 4$. This way, we assure that we are not picking up a one off spike in the data. For yearly data, we pick the value of the year in which the crisis starts.

${ }^{16}$ Most of these variables are relatively stable throughout our sample which is why we do not include them as separate variables in our main analysis since the cross-country differences are already picked up by the country fixed effects; however, we do include them separately as a robustness check and find qualitatively the same results.

${ }^{17}$ Both female participation and share of young workers were included in the exercise. The impulse response function for share of female workers can be found in the Appendix (Figure 9); the share of young workers was not found to be significant.

${ }^{18}$ Low skilled is defined as having attained up to lower secondary education. Countries with a high share of low skilled are Spain, Portugal and Greece. 
${ }^{19}$ Countries with a high share of female workers include Portugal, France and Finland.

${ }^{20}$ One explanation for this could be the fact that the other variables are expressed as deviations from the euro area aggregate. We have shown that the euro area as a whole exhibits an outward shift. Since the effects of the other variables are fixed to be zero on average, the overall shift of the Beveridge curve needs to be picked up by the simple crisis dummy.

${ }^{21}$ The strong sectoral dimension of the recent crisis has been well documented. See, for instance, ECB (2012).

${ }^{22}$ Including other sectors were tested but not found to produce significant results. The pre-crisis proportion of workers employed in industry, finance and business and nonmarket services does not seem to have a significant effect on the position of the Beveridge curve.

${ }^{23}$ It is well documented that homeowners are unwilling to sell their house below the price at which they bought it even if it is considered the market price-see for instance Genesove and Mayer (1997); Genesove and Mayer (2001); Ferreira et al. (2010) and Goetz (2013).

${ }^{24}$ See Appendix for financial slack results. Non-performing loans were also tested but also not found to be of significance.

\section{Appendix}
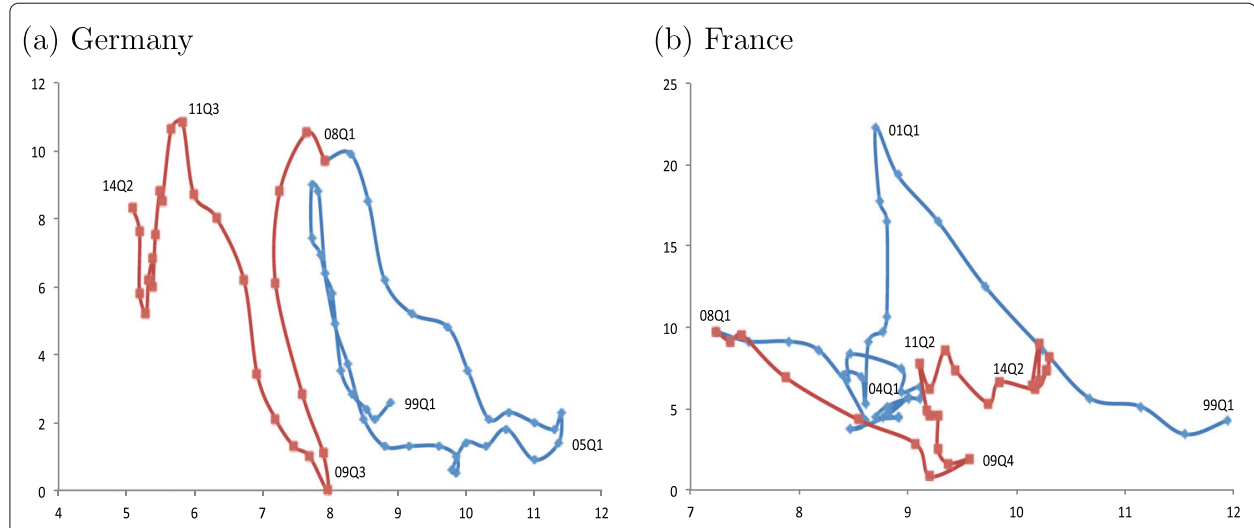

(c) Italy

(d) Spain
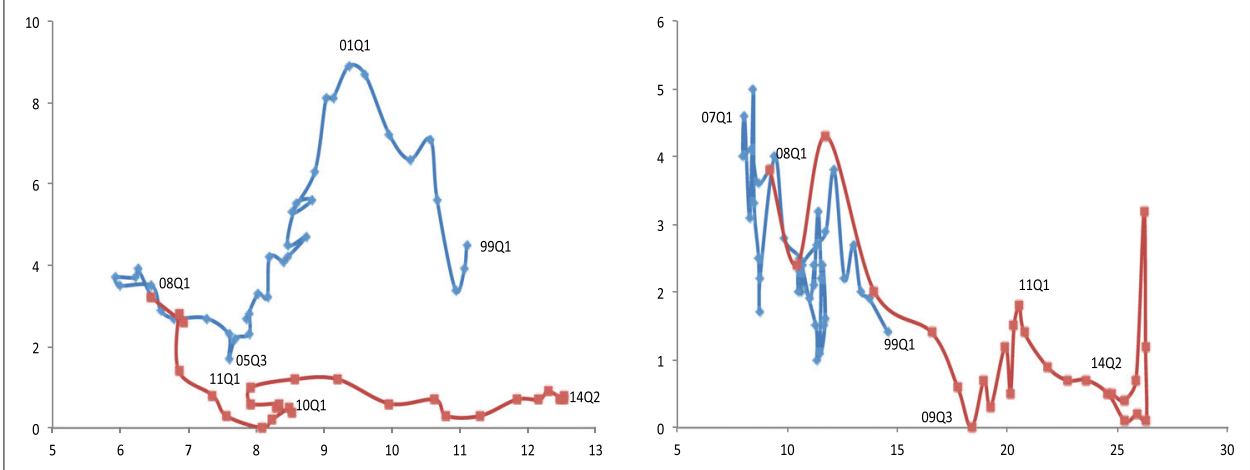

99Q1 - 08Q1 (-), 08Q1-14Q2 (-)

Fig. 8 Movements of the Beveridge curve for the four largest euro area economies. Notes: X-axis: unemployment rate (\%); y-axis: labour shortages (\%). Sources: Eurostat, European Commission 


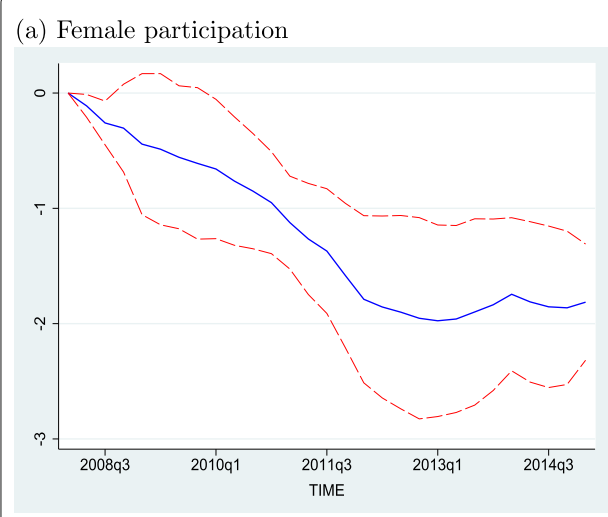

(b) Financial slack

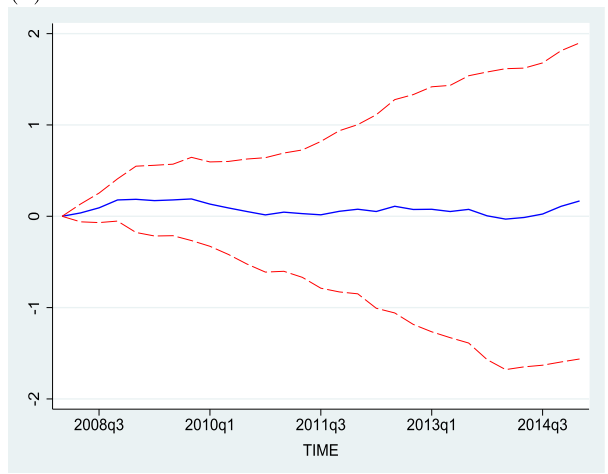

Local projection (-), 95\% confidence interval (-- )

Fig. 9 Female employment and financial conditions. Notes: Female: female share of the labour force. Financial slack: inverse of financial shortages

\section{Additional file}

Additional file 1: Supplementary appendix. (PDF 508 kb)

\section{Acknowledgements}

The opinions expressed in this paper are those of the authors and do not necessarily reflect the views of the ECB, the Bank of Finland, the Deutsche Bundesbank or the Eurosystem. Parts of this paper appeared in an earlier working paper entitled "What's going on behind the euro area Beveridge Curve(s)?" by the same authors. We thank Bob Anderton, Davide Furceri, Mario Izquierdo Peinado, Óscar Jordà, Mika Kuismanen, Jennifer Smith, Rob Valletta, participants of the ESCB Structural Issues Report 2012 Taskforce, the Finnish Economic Association XXXIV Annual Meeting, the IMF Jobs and Growth Seminar and the 9th ECB/CEPR Labour Market Workshop for very helpful comments and discussions. We would also like to thank the anonymous referee and the editor for the useful remarks. All errors are our responsibility. Responsible editor: Juan Jimeno

\section{Competing interests}

The IZA Journal of Labor Policy is committed to the IZA Guiding Principles of Research Integrity. The authors declares that they have observed these principles.

\section{Author details}

${ }^{1}$ Deutsche Bundesbank, Wilhelm-Epstein-Strasse 14, 60431 Frankfurt, Germany. ${ }^{2}$ University of Amsterdam, Amsterdam, The Netherlands. ${ }^{3}$ European Central Bank, Sonnemannstrasse 20, 60314 Frankfurt, Germany. ${ }^{4}$ Bank of Finland, P.O. Box 160 Helsinki, Finland.

Received: 11 September 2015 Accepted: 8 October 2016

Published online: 10 November 2016

\section{References}

Barnichon R, Elsby M, Hobijn B, Sahin A (2012) Which Industries are Shifting the Beveridge Curve? Monthly Labor Review:25-37

Barnichon R, Figura A (2011) What drives matching efficiency? A tale of composition and dispersion. Finance and Economics Discussion Series 2011-10, Board of Governors of the Federal Reserve System (U.S.)

Bernal-Verdugo LE, Furceri D, Guillaume D (2013) Banking crises, labor reforms, and unemployment. J Comp Econ 41(4):1202-1219

Bonthuis B, Jarvis V, Vanhala J (2013) What's going on behind the euro area Beveridge curve(s)? Working Paper Series 1586. European Central Bank

Bonthuis, B, Jarvis V, Vanhala J (2015) Shifts in euro area Beveridge curves and their determinants. Research Discussion Papers 2/2015. Bank of Finland

Borsch-Supan AH (1991) Panel data analysis of the Beveridge curve: is there a macroeconomic relation between the rate of unemployment and the vacancy rate Economica 58(231):279-97

Bouvet $F$ (2012) The Beveridge curve in Europe: new evidence using national and regional data. Appl Econ Taylor \& Francis J 44(27):3585-3604

Daly MC, Hobijn B, Sahin A, Valletta RG (2012) A search and matching approach to labor markets: did the natural rate of unemployment rise J Econ Perspect 26(3):3-26

Daly MC, Hobijn B, Valletta RG (2011 ) The recent evolution of the natural rate of unemployment. IZA Discussion Papers 5832, Institute for the Study of Labor (IZA) 
ECB (2002) Labour market mismatches in the euro area. Occasional paper series. European Central Bank ECB (2012) Euro area labour markets and the crisis. Occasional Paper Series 138. European Central Bank

ECB (2015) Comparisons and contrasts of the impact of the crisis on euro area labour markets. Occasional Paper Series 159. European Central Bank

Elsby MWL, Hobijn B, Sahin A (2010) The labor market in the great recession. Brook Pap Econ Act 41 (1 (Spring):1-69 European Commission (2011a) http://ec.europa.eu/economy_finance/db_indicators/surveys/index_en.htm

European Commission (2011 b) Labour market developments in Europe, 2011. European Economy No. 5, Directorate General for Economic and Financial Affairs

Ferreira F, Gyourko J, Tracy J (2010) Housing busts and household mobility. J Urban Econ 68(1):34-45

Genesove D, Mayer C (2001) Loss aversion and seller behavior: evidence from the housing market. Q J Econ MIT Press 116(4):1233-1260

Genesove D, Mayer CJ (1997) Equity and time to sale in the real estate market. Am Econ Rev 87(3):255-69

Goetz CF (2013) Falling house prices and labor mobility: evidence from matched employer-employee data. Working

Papers, Center for Economic Studies, U.S. Census Bureau 13-43, Center for Economic Studies, U.S. Census Bureau

Groenewold N (2003) Long-run shifts of the beveridge curve and the frictional unemployment rate in Australia. Aust J Labour Econ (AJLE) 6(1):65-82

Hobijn B, Sahin A (2013) Beveridge Curve Shifts across Countries since the Great Recession. IMF Economic Review 61(4):566-600

Jordà O (2005) Estimation and inference of impulse responses by local projections. Am Econ Rev 95(1):161-182

Sahin A, Song J, Topa G, Violante GL (2014) Mismatch unemployment. Am Econ Rev 104(11):3529-3564

Teulings CN, Zubanov N (2014) Is Economic Recovery A Myth? Robust Estimation Of Impulse Responses. J Appl Econ 29(3):497-514

Valletta RG (2005) Why has the U.S. Beveridge curve shifted back? New evidence using regional data. Working Paper Series 2005-25. Federal Reserve Bank of San Francisco

Wall HJ, Zoega G (2002) The British Beveridge curve: a tale of ten regions. Oxf Bull Econ Stat 64(3):261-80

\section{Submit your manuscript to a SpringerOpen ${ }^{\circ}$ journal and benefit from:}

- Convenient online submission

Rigorous peer review

- Immediate publication on acceptance

- Open access: articles freely available online

- High visibility within the field

Retaining the copyright to your article

Submit your next manuscript at $\gg$ springeropen.com 